\title{
Non-synonymous single-nucleotide variations of the human oxytocin receptor gene and autism spectrum disorders: a case-control study in a Japanese population and functional analysis
}

\author{
Wen-Jie Ma', Minako Hashii ${ }^{1}$, Toshio Munesue ${ }^{2}$, Kenshi Hayashi ${ }^{3}$, Kunimasa Yagii, Masakazu Yamagishi ${ }^{4}$,
} Haruhiro Higashida ${ }^{1,2,5,6}$ and Shigeru Yokoyama ${ }^{1,2,5,6^{*}}$

\begin{abstract}
Background: The human oxytocin receptor (hOXTR) is implicated in the etiology of autism spectrum disorders (ASDs) and is a potential target for therapeutic intervention. Several studies have reported single-nucleotide polymorphisms (SNPS) of the OXTR gene associated with ASDs. These SNPs, however, reside outside the protein-coding region. Not much is known about genetic variations that cause amino acid substitutions that alter receptor functions.

Methods: Variations in the OXTR gene were analyzed in 132 ASD patients at Kanazawa University Hospital in Japan and 248 unrelated healthy Japanese volunteers by re-sequencing and real-time polymerase chain reaction-based genotyping. Functional changes in variant OXTRs were assessed by radioligand binding assay and measurements of intracellular free calcium concentrations $\left(\left[\mathrm{Ca}^{2+}\right]_{\mathrm{i}}\right)$ and inositol 1,4,5-trisphosphate $\left(\mathrm{IP}_{3}\right)$ levels.

Results: Six subjects (4.5\%) in the ASD group and two in the control group (0.8\%) were identified as heterozygotes carrying the R376G variation ( $r 535062132 ; c .1126 \mathrm{C}>\mathrm{G}$ ); one individual from the ASD group (0.8\%) and three members of the control group (1.2\%) were found to be carrying R376C (c.1126C>T). The C/G genotype significantly correlated with an increased risk of ASDs (odds ratio $(O R)=5.83 ; 95 \%$ confidence interval $(C l)=1.16$ to 29.33; $P=0.024$, Fisher's exact test). Consistently, the $\mathrm{G}$ allele showed a correlation with an increased likelihood of $\mathrm{ASD}$ ( $\mathrm{OR}=5.73 ; 95 \% \mathrm{Cl}=1.15$ to 28.61; $P=0.024$, Fisher's exact test). The frequencies of the C/T genotype and the T allele in the ASD and control groups did not differ significantly. We also examined changes in agonist-induced cellular responses mediated by the variant receptors hOXTR-376G and hOXTR-376C. OXT-induced receptor internalization and recycling were faster in hOXTR-376Gexpressing HEK-293 cells than in cells expressing hOXTR-376R or hOXTR-376C. In addition, the elevation in $\left[\mathrm{Ca}^{2+}\right]_{i}$ and $\mathrm{IP}_{3}$ formation decreased in the cells expressing hOXTR-376G and hOXTR-376C tagged with enhanced green fluorescent protein (EGFP), in comparison with the cells expressing the common-type hOXTR-376R tagged with EGFP.
\end{abstract}

Conclusions: These results suggest that the rare genetic variation rs35062132 might contribute to the pathogenesis of ASDs, and could provide a molecular basis of individual differences in OXTR-mediated modulation of social behavior.

Keywords: Autism spectrum disorders, Inositol-1,4,5-trisphosphate, Intracellular free calcium, Oxytocin, Oxytocin receptor, Single-nucleotide variation

\footnotetext{
*Correspondence: shigeruy@med.kanazawa-u.ac.jp

1 Department of Biophysical Genetics, Kanazawa University Graduate School

of Medicine, 13-1 Takara-machi, Kanazawa 920-8640, Japan

${ }^{2}$ Research Center for Child Mental Development, Kanazawa University,

Kanazawa 920-8640, Japan

Full list of author information is available at the end of the article
} 


\section{Background}

Oxytocin (OXT) is a nonapeptide hormone primarily produced by magnocellular neurons in the paraventricular and supraoptic nuclei of the hypothalamus [1-6]. Oxytocin is secreted into the systemic circulation via the hypothalamic-neurohypophyseal system and transported to exert its peripheral effects, such as uterine contractions and milk ejection [1-6]. Oxytocin is released into the brain from dendrites [7] or centrally projected axonal terminals [8], and it acts on various areas of the central nervous system, modulating affiliative and social behaviors, emotional states, and cognitive functions in many animal species [1-6].

The actions of OXT are mediated by the OXT receptor (OXTR), which belongs to the GTP-binding proteincoupled receptor family [9]. It is well established that the OXTR is coupled to heterotrimeric $G_{q / 11}$ protein and that it stimulates phospholipase $\mathrm{C}_{\beta}\left(\mathrm{PLC}_{\beta}\right)$, leading to the production of inositol 1,4,5-trisphosphate $\left(\mathrm{IP}_{3}\right)$ and 1,2-diacylglycerol (DAG) [9]. Inositol 1,4,5-trisphosphate induces an increase in intracellular calcium concentration $\left(\left[\mathrm{Ca}^{2+}\right]_{\mathrm{i}}\right)$ by triggering $\mathrm{IP}_{3}$ receptor-mediated $\mathrm{Ca}^{2+}$ release from intracellular stores, whereas DAG activates protein kinase $C$ (PKC), which phosphorylates downstream signaling molecules [9]. Upon prolonged agonist stimulation, OXTR undergoes desensitization and internalization through phosphorylation by GPCR kinase 2 (GRK2) and subsequent interaction with $\beta$-arrestin 2 [9-13]. The internalized OXTRs are then recycled to the cell surface via vesicles containing small GTPases, Rab4 and Rab5 [13].

Previous studies have shown that impaired OXTRmediated signaling causes behavioral abnormalities [2,6,14]. Mice deficient in the OXTR gene show diminished social discrimination, increased aggressive behavior, reduced cognitive flexibility, and increased susceptibility to seizures $[15,16]$. Using homozygous mutant mice lacking CD38, a transmembrane protein with ADP-ribosyl cyclase activity, we have shown that a decrease in the formation of cyclic ADP-ribose (cADPR) results in dysfunction of $\mathrm{Ca}^{2+}$-induced $\mathrm{Ca}^{2+}$ release for OXT secretion in hypothalamic neurons. The reduction in CADPR levels also causes marked defects in maternal nurturing and social behaviors similar to those observed in OXT- and OXTR-knockout mice $[17,18]$. We also demonstrated that ADP-ribosyl cyclase activity increases after OXTR stimulation, regulating OXT release in the hypothalamus and pituitary in adult male mice [19].

In humans, OXTR has been implicated in the pathogenesis of neuropsychiatric disorders and considered a potential target for therapeutic intervention [20]. Gregory et al. [21] have reported a heterozygous deletion of the OXTR gene, located on chromosome $3 \mathrm{p} 25$, in a patient with autism whose mother had a putative obsessive-compulsive disorder. In addition, many studies have demonstrated that single-nucleotide polymorphisms (SNPs) of the OXTR gene are associated with autism spectrum disorders (ASDs), social anxiety disorders, and schizophrenia [22-29]. However, all SNPs reported so far reside outside the protein-coding region, and their functional importance is unclear. If allelic variations leading to amino acid substitutions in the OXTR gene were associated with these neuropsychiatric disorders, then such variations would help to predict the etiological relevance based on protein structure-function relationship and to introduce individualized OXT-based therapy.

Therefore, we analyzed nucleotide variations in the protein-coding regions of the human OXTR gene in ASD patients and unrelated healthy controls. Furthermore, we focused on a triallelic variation (rs35062132; c.1126C> $\mathrm{G} / \mathrm{T}$; the nomenclature of variation recommended by the Human Genome Variation Society [30]) and investigated whether the amino acid substitution R376G/C causes any changes in OXTR-mediated cellular responses.

\section{Methods \\ Participants}

We recruited 132 ASD subjects (102 males, 30 females; $15.9 \pm 0.7$ years) from the outpatient psychiatry department of the Kanazawa University Hospital. All subjects fulfilled the DSM-IV criteria for pervasive developmental disorder. The diagnoses were made by two experienced child psychiatrists through interviews and clinical record reviews as described previously [31], and the subjects had no apparent physical anomalies. The two experienced child psychiatrists independently confirmed the diagnosis of ASD for all patients by semi-structured behavior observation and interviews with the subjects and their parents. During each of these interviews with parents, which were helpful in the evaluation of autism-specific behaviors and symptoms, the examiners used one of the following methods: the Asperger Syndrome Diagnostic Interview [32], the Autism Diagnostic Interview-Revised (ADI-R) [33], the Pervasive Developmental Disorders Autism Society Japan Rating Scale [34], the Diagnostic Interview for Social and Communication Disorders [35], or the Tokyo Autistic Behavior Scale [36]. Based on these evaluation methods, 97 patients were classified as autistic disorder (autism), 10 as Asperger's disorder, and 25 as pervasive developmental disorder not otherwise specified (PDD-NOS). The 248 controls (143 males, 105 females; $31.3 \pm 0.6$ years) were unrelated healthy Japanese volunteers. All patients and controls were Japanese with no non-Japanese parents or grandparents. This study was approved by the ethics committees of Kanazawa University School of Medicine. All examinations were performed after informed consent according to the Declaration of Helsinki. 


\section{Re-sequencing}

Genomic DNA was extracted from venous blood samples using the Wizard Genomic DNA Purification kit (Promega, Madison, WI, USA), or from nails using the ISOHAIR DNA extraction kit (Nippon Gene, Tokyo, Japan). DNA fragments containing exons 3 and 4 of the hOXTR gene were amplified by PCR in a $20-\mu \mathrm{l}$ reaction mixture containing $2.5 \mathrm{ng}$ genomic DNA, $200 \mu \mathrm{M}$ dNTPs, $200 \mathrm{nM}$ of each primer, $4 \mu \mathrm{l}$ Ampdirect G/C (Shimadzu, Kyoto, Japan), $4 \mu$ l Ampdirect-4 (Shimadzu), and 1 unit Ex Taq DNA polymerase (Takara Shuzo, Otsu, Japan). The amplification procedure consisted of denaturation at $96^{\circ} \mathrm{C}$ for 1 min, followed by 35 cycles of $96^{\circ} \mathrm{C}$ for $30 \mathrm{~s}, 65^{\circ} \mathrm{C}$ for 1 $\min$, and $72^{\circ} \mathrm{C}$ for $1 \mathrm{~min}$. The primers used were FWD1 or FWD4 and REV1 for exon 3, and FWD5 and REV3 for exon 4 (sequences are given in Table 1). After amplification, PCR products were purified with the High Pure PCR Cleanup Micro kit (Roche, Mannheim, Germany), subjected to cycle sequencing reaction (BigDye version 1.1; Applied Biosystems, Foster City, CA, USA) according to the manufacturer's protocol, and analyzed on an ABI PRISM 310 Genetic Analyzer (Applied Biosystems). The primers used were FWD1-FWD5 and REV1-REV6 (Table 1).

\section{Real-time PCR}

Two primers, FWD8 and REV7 (Table 1), were designed to amplify a 138-bp product encompassing rs35602132 at the mRNA position 1748 (g.8734707; c.1126). Three custom-designed TaqMan minor groove binder (MGB) probes were obtained from Applied Biosystems: 376GFAM and 376C-FAM targeted to the variant alleles, and 376R-VIC to the common allele (Table 1). PCR was performed in 20- $\mu \mathrm{l}$ mixtures containing $10 \mu \mathrm{l}$ TaqMan universal master mix (Applied Biosystems), $200 \mathrm{nM}$ of each primer, $100 \mathrm{nM}$ 376R-FAM, $100 \mathrm{nM}$ 376G-VIC or 376C-VIC, and $10 \mathrm{ng}$ of sample DNA. Thermocycling was performed on the ViiA 7 Real-Time PCR System (Applied Biosystems). The amplification was conducted at $60^{\circ} \mathrm{C}$ for $30 \mathrm{~s}, 95^{\circ} \mathrm{C}$ for $5 \mathrm{~min}$, and 40 cycles of $95^{\circ} \mathrm{C}$ for $15 \mathrm{~s}$ and $60^{\circ} \mathrm{C}$ for $1 \mathrm{~min}$. Data were analyzed with SDS2.3 software (Applied Biosystems).

\section{Site-directed mutagenesis}

cDNAs encoding hOXTR variants at amino acid residue 376 were generated by site-directed mutagenesis as described previously [37]. pCHOXTR [38] harboring hOXTR-376R, a common-type receptor, was used as a template for PCR; the primers used were R376G-FWD and R376G-REV (Table 1) for the R376G substitution, and R376C-FWD and R376C-REV (Table 1) for R376C. The amplified products were treated with EX Taq DNA polymerase (Takara Shuzo) at $72^{\circ} \mathrm{C}$ for $10 \mathrm{~min}$ and cloned into a pCR2.1-TOPO vector (Invitrogen,
Carlsbad, CA, USA) to yield pCHOXTR-376G and pCHOXTR-376C. The cDNA inserts were verified by nucleotide sequencing.

\section{Construction of expression plasmids}

The 1.4-kb EcoRI fragments from pCHOXTR [38], pCHOXTR-376G, and pCHOXTR-376C were cloned into the EcoRI site of the mammalian expression plasmid pcDNA3.1 (+) (Invitrogen) to yield pcDNAHOXTR376R, pcDNAHOXTR-376G, and pcDNAHOXTR-376C, respectively.

In some experiments, hOXTRs of the common type and variants were fused to the enhanced green fluorescent protein (EGFP). Expression plasmids for these fusion proteins were constructed essentially as described previously [38]. In brief, the 1.4-kb EcoRI fragments obtained from pCHOXTR [38], pcDNAHOXTR-376G, and pcDNAHOXTR-376C were subjected to PCR using primers EGFP-FWD and EGFP-REV (Table 1). The amplified fragments were cleaved with PstI and BamHI. The resulting 0.46-kb PstI (1334)/BamHI (primer) fragments and the 0.78-kb BamHI (556)/PstI (1334) fragment from pCHOXTR were ligated to $B a m \mathrm{HI} / B g l \mathrm{II}$-cleaved pEGFP-N3 (Clontech) to yield pHOXTR-376R-EGFP, pHOXTR-376G-EGFP, and pHOXT-R376C-EGFP. Restriction endonucleasesites are identified by numbers (in parentheses; in accordance with the data deposited in GenBank under accession number NM_000916) indicating the 5 '-terminal nucleotide generated by cleavage.

\section{Cell culture and transfection}

Human embryonic kidney HEK-293 cells and COS-7 cells were maintained in DMEM supplemented with $10 \% \mathrm{FBS}$ at $37^{\circ} \mathrm{C}$ in a humidified atmosphere of $95 \%$ air and 5\% $\mathrm{CO}_{2}$. NG108-15 neuroblastoma $\times$ glioma hybrid cells were cultured as described previously [39]. Cells were grown in culture dishes to 80 to $90 \%$ confluence and transfected with expression plasmids using FuGENE HD Transfection Reagent (Roche) following the manufacturer's instruction.

\section{Radioligand binding assay}

COS-7 cells transfected with pcDNAHOXTR-376R, pcDNAHOXTR-376G, pcDNAHOXTR-376C, or pcDNA3.1 $(+)$ were collected $48 \mathrm{~h}$ after transfection, and resuspended in homogenization buffer (25 mM Tris, $\mathrm{pH} 7.4,1 \mathrm{mM}$ EDTA, $250 \mathrm{mM}$ sucrose). The cells were homogenized and centrifuged at $1,500 \mathrm{~g}$ at $4^{\circ} \mathrm{C}$ for $10 \mathrm{~min}$, to pellet nuclei and intact cells. The resulting supernatants were centrifuged at $40,000 \mathrm{~g}$ at $4^{\circ} \mathrm{C}$ for $30 \mathrm{~min}$, and crude membrane pellets were suspended in binding buffer containing $50 \mathrm{mM}$ HEPES ( $\mathrm{pH} 7.4$ ), $5 \mathrm{mM} \mathrm{MgCl}_{2}, 1 \mathrm{mM} \mathrm{CaCl}_{2}$, and $0.2 \%$ BSA. Protein concentration was determined by the bicinchoninic acid assay (Pierce, Rockford, IL, USA) using 
Table 1 Oligonucleotides used in this study

\begin{tabular}{|c|c|c|c|c|}
\hline \multirow[t]{2}{*}{ Nucleotide sequencing } & \multicolumn{2}{|c|}{ Real-time PCR-based genotyping } & \multirow[t]{2}{*}{ Site-directed mutagenesis } & \multirow[t]{2}{*}{ EGFP tagging } \\
\hline & Amplification & TaqMan MGB probes & & \\
\hline $\begin{array}{l}\text { FWD1: } \\
\text { TGGACTCAGCAGATCCGTCCG }\end{array}$ & $\begin{array}{l}\text { FWD8: } \\
\text { GCTCCGCCAGCTACCTGAAG }\end{array}$ & 376G-FAM: TGAGCCATGGCAGCTCC & $\begin{array}{l}\text { R376G-FWD: } \\
\text { CCTITGTCCTGAGCCATGGCAGCTCCAGCCAGAGG }\end{array}$ & EGFP-FWD: CCGCAGGTGCACATCTTCTC \\
\hline $\begin{array}{l}\text { FWD2: } \\
\text { CTAAGCATCGCCGACCTGGT }\end{array}$ & $\begin{array}{l}\text { REV7: } \\
\text { TGGTGGGTCACGCCGTGGAT }\end{array}$ & 376R-VIC: TGAGCCATCGCAGCTCC & $\begin{array}{l}\text { R376G-REV: } \\
\text { CCTCTGGCTGGAGCTGCCATGGCTCAGGACAAAGG }\end{array}$ & EGFP-REV: GTGGATCCCGCCGTGGATGG \\
\hline $\begin{array}{l}\text { FWD3: } \\
\text { CCGCAGGTGCACATCTTCTC }\end{array}$ & & 376C-FAM: TGAGCCATTGCAGCTCC & $\begin{array}{l}\text { R376C-FWD: } \\
\text { CCTITGTCCTGAGCCATI_GCAGCTCCAGCCAGAGG }\end{array}$ & \\
\hline $\begin{array}{l}\text { FWD4: } \\
\text { TGGAGTCTCCAGGAGTGGA }\end{array}$ & & & $\begin{array}{l}\text { R376C-REV: } \\
\text { CCTCTGGCTGGAGCTGCAATGGCTCAGGACAAAGG }\end{array}$ & \\
\hline \multicolumn{5}{|l|}{$\begin{array}{l}\text { FWD5: } \\
\text { GTCTGGAAGTGGCTCCAGTG } \\
\end{array}$} \\
\hline \multicolumn{5}{|l|}{$\begin{array}{l}\text { REV1: } \\
\text { CCTGGACATTCTGAGGCAGC }\end{array}$} \\
\hline \multicolumn{5}{|l|}{$\begin{array}{l}\text { REV2: } \\
\text { GATGAGCTTGACGCTGCTGAC }\end{array}$} \\
\hline \multicolumn{5}{|l|}{$\begin{array}{l}\text { REV3: } \\
\text { GTCAGCAGCGTCAAGCTCATC }\end{array}$} \\
\hline \multicolumn{5}{|l|}{ REV4: CAGTCGAAGACGCCGTC } \\
\hline \multicolumn{5}{|l|}{ REV5: ACATGAGCAGCAGCAGG } \\
\hline REV6: CAGGAGCAGGATGAGAC & & & & \\
\hline
\end{tabular}


BSA as a standard. [Tyrosyl- $\left.{ }^{3} \mathrm{H}\right]$-oxytocin $\left(\left[{ }^{3} \mathrm{H}\right]-\mathrm{OXT}\right.$; PerkinElmer Life Sciences, Waltham, MA, USA) was diluted in the binding buffer to concentrations of 0.05 to 4 $\mathrm{nM}$. Specific binding assays were performed in $5-\mu \mathrm{g}$ cell membrane preparations incubated at room temperature for $1 \mathrm{~h}$ with increasing concentrations of $\left[{ }^{3} \mathrm{H}\right]$-OXT, in the absence or presence of 200-fold excess of unlabeled OXT. Binding reaction mixtures were filtered through a $\mathrm{GF} / \mathrm{C}$ glass fiber filter (Whatman, Maidstone, Kent, UK) and washed three times with Wash Buffer (50 mM HEPES, pH 7.4, $500 \mathrm{mM} \mathrm{NaCl}, 0.1 \% \mathrm{BSA})$. Radioactivity associated with membranes retained by glass filters was quantified in a liquid scintillation counter (LSC-5100; Aloka, Tokyo, Japan). Specific binding was calculated by subtracting non-specific binding in the presence of 200-fold excess of OXT at each radioligand concentration from total binding. Affinity $\left(K_{\mathrm{d}}\right)$ and maximal binding capacity $\left(B_{\max }\right)$ of saturation binding were obtained from saturation isotherm specific binding data by nonlinear regression curve analysis using the standard equation for a rectangular hyperbola fitted to one site with the GraphPad Prism 5 (GraphPad Software Inc., San Diego, CA, USA). Competition binding experiments were performed in duplicate by incubating $5 \mu \mathrm{g}$ of cell membranes at room temperature for $1 \mathrm{~h}$, in the same medium with $1 \mathrm{nM}\left[{ }^{3} \mathrm{H}\right]$-OXT and increasing concentrations of unlabeled OXT $\left(10^{-12}\right.$ to $\left.10^{-5} \mathrm{M}\right)$. $\log \mathrm{IC}_{50}$ values were derived from nonlinear least-squares analysis using the GraphPad Prism 5 software (GraphPad Software Inc.).

\section{Measurement of receptor recycling}

HEK-293 cells were plated on poly-D-ornithine-coated glass coverslips and cultured overnight. After transfection with pcDNAHOXTR-376R, pcDNAHOXTR-376G, or pcDNAHOXTR-376C, the cells were incubated at $37^{\circ} \mathrm{C}$ in serum-free DMEM for different times, in the absence or presence of OXT (100 nM). Reactions were stopped by removing the medium and fixing the cells with $4 \%$ paraformaldehyde at room temperature for $10 \mathrm{~min}$. The cells were then blocked with PBS containing 1\% BSA and $1.5 \%$ normal horse serum for $30 \mathrm{~min}$, and incubated with goat anti-OXTR antibody (N-19; 1:200; sc-8103, Santa Cruz Biotechnology, Santa Cruz, CA, USA) at $4^{\circ} \mathrm{C}$ overnight. After washing in PBS, the cells were incubated with donkey anti-goat IgG $(\mathrm{H}+\mathrm{L})$ antibody conjugated with Alexa Fluor 488 (1:500; Invitrogen) combined with 4',6-diamidino-2-phenylindole (DAPI; $1 \mu \mathrm{g} / \mathrm{ml}$; Dojindo, Kumamoto, Japan). In some experiments, $\mathrm{pSNAP}_{\mathrm{f}}-\mathrm{ADR} \beta 2$ (New England Biolabs, Ipswich, MA, USA), an expression plasmid for $\beta 2$ adrenergic receptor fused to $\mathrm{SNAP}_{\mathrm{f}}$, was cotransfected into HEK-293 cells. The cells were labeled with SNAP-Surface Alexa Fluor $488(2 \mu \mathrm{M}$; New England Biolabs), fixed with $4 \%$ paraformaldehyde, and reacted with goat anti-OXTR antibody (N-19; 1:200; Santa Cruz) at $4^{\circ} \mathrm{C}$ overnight, followed by incubation with donkey antigoat IgG $(\mathrm{H}+\mathrm{L})$ antibody conjugated with Alexa Fluor 594 (1:500; Invitrogen); none of the solutions contained any cell-permeabilizing reagents. Fluorescent images were obtained using confocal laser scanning microscopes (LSM5 Pascal; Carl Zeiss, Jena, Germany; FluoView FV10i, Olympus). Data were analyzed using the FV10ASW software (Olympus).

\section{$\left[\mathrm{Ca}^{2+}\right]_{\mathrm{i}}$ measurement}

We measured $\left[\mathrm{Ca}^{2+}\right]_{\mathrm{i}}$ using the fluorescent $\mathrm{Ca}^{2+}$ indicator fura-2-acetoxymethyl ester (fura-2/AM). HEK-293 cells or NG108-15 cells transfected with pHOXTR-376R-EGFP, pHOXTR-376G-EGFP, or pHOXTR-376C-EGFP were loaded with fura-2/AM to a final concentration of $3 \mu \mathrm{M}$ in complete medium and incubated at $37^{\circ} \mathrm{C}$. After 30-min loading, the cells were washed three times with HEPESbuffered saline (HBS) solution $(145 \mathrm{mM} \mathrm{NaCl}, 5 \mathrm{mM} \mathrm{KCl}$, $1 \mathrm{mM} \mathrm{MgCl}, 20 \mathrm{mM}$ HEPES-NaOH, $2 \mathrm{mM} \mathrm{CaCl}, 20$ $\mathrm{mM}$ glucose, $\mathrm{pH}$ 7.4). Cells expressing EGFP-tagged OXTRs were visualized at a wavelength of $488 \mathrm{~nm}$ before OXT application. The fluorescence of the cells loaded with fura- $2 / \mathrm{AM}$ was then measured at $37^{\circ} \mathrm{C}$, at the determined sites, through a pinhole (10 to $20 \mu \mathrm{m}$ in diameter). We used alternating excitation wavelengths of 340 and 380 $\mathrm{nm}$ in a $\mathrm{Ca}^{2+}$ microspectrofluorometric system (OSP-3 Model; Olympus, Tokyo, Japan), as described previously [39]. The $\mathrm{Ca}^{2+}$ emission was detected every $10 \mathrm{~s}$ for $5 \mathrm{~min}$ after OXT application. The ratio of fluorescence at $340 \mathrm{~nm}$ and $380 \mathrm{~nm}\left(F_{340} / F_{380}\right)$ was used to determine $\left[\mathrm{Ca}^{2+}\right]_{\mathrm{i}}$. All data were normalized to the baseline fluorescence $\left(F_{0}\right)$ recorded $10 \mathrm{~s}$ before OXT addition, and given as $F / F_{0}$.

\section{$\mathrm{IP}_{3}$ accumulation assay}

HEK-293 cells were plated at a density of approximately $5 \times 10^{4}$ per well in a 24-well plate, and transiently transfected with pcDNAHOXTR-376R, pcDNAHOXTR376G or pcDNAHOXTR-376C, or pcDNA3.1(+). Before treatment with OXT, the transfected cells were washed and incubated in HBS containing $2 \mathrm{mM} \mathrm{CaCl}_{2}, 10 \mathrm{mM}$ glucose, and $10 \mathrm{mM} \mathrm{LiCl}$ at $37^{\circ} \mathrm{C}$ for $10 \mathrm{~min}$. After OXT treatment, the reaction was terminated at designated time points by the addition of $50 \mu \mathrm{l}$ of $10 \%(\mathrm{w} / \mathrm{v})$ perchloric acid. The acid-soluble extract was neutralized with $150 \mu \mathrm{l}$ of $1.53 \mathrm{M} \mathrm{KOH}-75 \mathrm{nM}$ HEPES, and perchloric acid was precipitated on ice and removed by a brief centrifugation. The $\mathrm{IP}_{3}$ aqueous extract was then examined with an Inositol-1,4,5-triphosphate $\left[{ }^{3} \mathrm{H}\right]$-Radio Receptor Assay Kit (PerkinElmer Life Sciences).

\section{Statistical analyses}

Data obtained from genetic studies were analyzed using a contingency table and the Fisher's exact test (GraphPad Prism 5; GraphPad Software Inc.). All data from the 
in vitro studies are shown as mean \pm standard error of the mean. Statistical significance was determined by the Student's $t$ test or two-way analysis of variance (ANOVA) using an interactive fitting program (GraphPad Prism 5; GraphPad Software Inc.); $P$ values smaller than 0.05 were considered to be statistically significant.

\section{Results}

\section{Genetic analysis}

As the entire amino acid sequence of the hOXTR is encoded by exons 3 and 4, as illustrated in Figure 1A, we initially re-sequenced both exons for genetic variations. Of 27 single-nucleotide variations listed in the NCI dbSNP database, we detected minor alleles of rs4686302, rs151257822, and rs35062132 in 59 ASD patients and 30 unrelated healthy Japanese volunteers (Figure 1A, Table 2). As c.1126 G>C (rs35062132; R376G) was detected in two ASD patients but not in controls (Table 2, Figure 1B), we selected rs35062132 for further analysis.

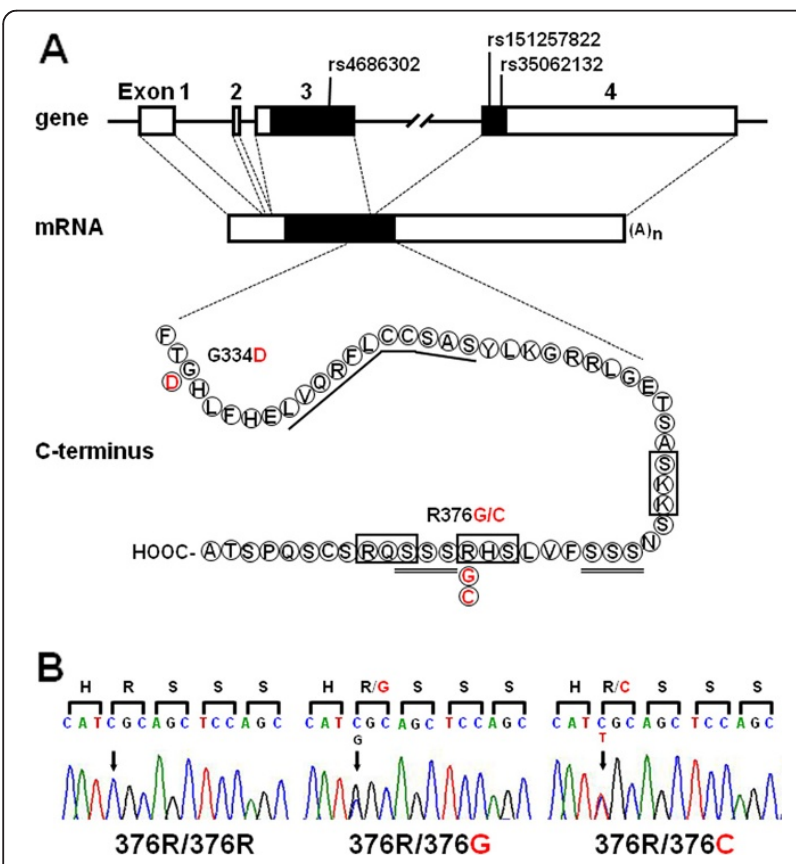

Figure 1 Triallelic variation rs35062132 in the human OXTR gene.

(A) Structure of the human OXTR gene and amino acid sequence of the C-terminal portion of the human OXTR. White and black blocks represent untranslated regions and protein-coding regions, respectively, and red letters represent minor amino acid variations. Indicated in the protein-coding region are rs4686302, rs151257822, and rs35062132, in which allelic heterozygosity was detected in this study. The region required for coupling to $\mathrm{Gq}$ isunderlined; potential PKC phosphorylation sites are indicated by boxes, and Ser triplets are double underlined. (B) Representative electrophoretograms of the rs35062132 (c.1126C>G/T; R376G/C). Left, homozygote for the common allele (376R/376R); middle, heterozygous carrier of c.1126C>G (376R/376G); right, heterozygous carrier of c.1126C>T (376R/376C).

Arrows indicate the polymorphic position. Nucleotides and amino acids for minor alleles are shown in red.
We genotyped an additional 73 ASD patients and 218 healthy volunteers for rs35062132 variation using the TaqMan-based real-time PCR method. In total, we obtained data from 132 ASD patients and 248 controls. Six individualsin the ASD group (4.5\%) and two in the control group $(0.8 \%)$ were identified as heterozygotes carrying the R376G variation (rs35062132; c.1126C>G). One person in the ASD group (0.8\%) and three in the control group (1.2\%) carried R376C (c.1126C $>\mathrm{T}$; Table 3). No homozygous carriers for the minor alleles were observed. The $X^{2}$ goodness-of-fit test showed that the genotype frequency distribution of rs35062132 did not deviate from Hardy-Weinberg equilibrium in the patient group $\left(\chi^{2}=0.098, P=0.99\right)$ or the control group $\left(\chi^{2}=\right.$ $0.026, P=1.00)$. The genotype and allele frequencies of rs35062132 obtained from all participants are summarized in Table 3 . The $\mathrm{C} / \mathrm{G}$ genotype was significantly correlated with an increased risk of ASDs (odds ratio $(\mathrm{OR})=5.83$; $95 \%$ confidence interval $(\mathrm{CI})=1.16$ to 29.3 ; $P=0.024$, Fisher's exact test; Table 3). Consistently, the $\mathrm{G}$ allele also showed a correlation with an increased likelihood of ASDs $(\mathrm{OR}=5.73,95 \% \mathrm{CI}=1.15$ to 28.6; $P=0.024$, Fisher's exact test; Table 3 ). The frequencies of the $\mathrm{C} / \mathrm{T}$ genotype and the $\mathrm{T}$ allele did not significantly differ between the ASD and control groups (Table 3).

\section{Radioligand binding properties of the common and variant hOXTRs}

To find out whether the amino acid changes at the residue 376 affect the receptor functions, we compared ligand-binding properties of the common and variant hOXTRs. In saturation binding and Scatchard analysis of ${ }^{3}[\mathrm{H}]$-OXT binding to membranes prepared from COS-7 cells transfected with hOXTR-expression plasmids, the variants hOXTR-376G and hOXTR-R376C, as well as the common-type hOXTR-376R, exhibited single highaffinity binding sites. Values of $K_{\mathrm{d}}$ were $0.90 \pm 0.28,1.1 \pm$ 0.12 , and $1.2 \pm 0.19 \mathrm{nM}$ ( $n=15$ in each group), and values of $B_{\max }$ were $3153 \pm 531,3202 \pm 234$, and $3120 \pm 339$ $\mathrm{fmol} / \mathrm{mg}$ of protein ( $n=15$ in each group) for hOXTR376R, hOXTR-376G, and hOXTR-376C, respectively. Competition binding experiments confirmed that the variant and common receptors did not differ significantly: values of $\mathrm{IC}_{50}$ were $1.05 \pm 0.47,0.49 \pm 0.23$, and $0.71 \pm$ $0.30 \mathrm{nM}(n=15$ in each group) for hOXTR-376R, hOXTR-376G, and hOXTR-376C, respectively. These data indicate that both variations have no or little effect on OXT binding.

\section{Agonist-induced receptor internalization and recycling in HEK-293 cells}

We then examined the agonist-induced internalization and recycling of hOXTRs in HEK-293 cells, which have been most extensively used for investigation of GPCR 
Table 2 Frequency of non-synonymous single-nucleotide variations in the OXTR gene detected by re-sequencing

\begin{tabular}{|c|c|c|c|c|c|c|}
\hline \multirow[t]{2}{*}{${\mathrm{dbSNP}-I \mathrm{D}^{\mathrm{a}}}$} & \multirow{2}{*}{$\begin{array}{l}\text { mRNA }^{b} \\
\text { position }\end{array}$} & \multirow[t]{2}{*}{ Allele } & \multirow{2}{*}{$\begin{array}{l}\text { Amino acid } \\
\text { position }\end{array}$} & \multirow{2}{*}{$\begin{array}{l}\text { Amino acid } \\
\text { residue }\end{array}$} & \multicolumn{2}{|l|}{ Number of cases } \\
\hline & & & & & ASD $(n=59)$ & Control $(n=30)$ \\
\hline rs 237908 & 19 & $T / G$ & 7 & $\mathrm{~S} / \mathrm{A}$ & $\mathrm{T} / \mathrm{T}(0) \mathrm{T} / \mathrm{G}(0) \mathrm{G} / \mathrm{G}(59)$ & $\mathrm{T} / \mathrm{T}(0) \mathrm{T} / \mathrm{G}(0) \mathrm{G} / \mathrm{G}(30)$ \\
\hline rs237907 & 40 & $T / G$ & 14 & S/A & $\mathrm{T} / \mathrm{T}(0) \mathrm{T} / \mathrm{G}(0) \mathrm{G} / \mathrm{G}(59)$ & $\mathrm{T} / \mathrm{T}(0) \mathrm{T} / \mathrm{G}(0) \mathrm{G} / \mathrm{G}(30)$ \\
\hline rs237906 & 46 & $\mathrm{~T} / \mathrm{G}$ & 16 & $\mathrm{~S} / \mathrm{A}$ & $\mathrm{T} / \mathrm{T}(0) \mathrm{T} / \mathrm{G}(0) \mathrm{G} / \mathrm{G}(59)$ & $\mathrm{T} / \mathrm{T}(0) \mathrm{T} / \mathrm{G}(0) \mathrm{G} / \mathrm{G}(30)$ \\
\hline rs189386 & 64 & $\mathrm{~T} / \mathrm{G}$ & 22 & W/G & $\mathrm{T} / \mathrm{T}(0) \mathrm{T} / \mathrm{G}(0) \mathrm{G} / \mathrm{G}(59)$ & $\mathrm{T} / \mathrm{T}(0) \mathrm{T} / \mathrm{G}(0) \mathrm{G} / \mathrm{G}(30)$ \\
\hline rs113718500 & 65 & $\mathrm{C} / \mathrm{G}$ & 22 & $\mathrm{~A} / \mathrm{G}$ & $\mathrm{C} / \mathrm{C}(0) \mathrm{C} / \mathrm{G}(0) \mathrm{G} / \mathrm{G}(59)$ & $\mathrm{C} / \mathrm{C}(0) \mathrm{C} / \mathrm{G}(0) \mathrm{G} / \mathrm{G}(30)$ \\
\hline rs 237903 & 86 & $\mathrm{~T} / \mathrm{C}$ & 29 & $\mathrm{~V} / \mathrm{A}$ & $\mathrm{T} / \mathrm{T}(0) \mathrm{T} / \mathrm{C}(0) \mathrm{C} / \mathrm{C}(59)$ & $\mathrm{T} / \mathrm{T}(0) \mathrm{T} / \mathrm{C}(0) \mathrm{C} / \mathrm{C}(30)$ \\
\hline rs171114 & 188 & $\mathrm{G} / \mathrm{C}$ & 63 & $\mathrm{G} / \mathrm{A}$ & G/G (0) G/C (0) C/C (59) & $\mathrm{G} / \mathrm{G}(0) \mathrm{G} / \mathrm{C}(0) \mathrm{C} / \mathrm{C}(30)$ \\
\hline rs143644523 & 220 & $\mathrm{~T} / \mathrm{C}$ & 74 & $F / L$ & $\mathrm{~T} / \mathrm{T}(0) \mathrm{T} / \mathrm{C}(0) \mathrm{C} / \mathrm{C}(59)$ & $\mathrm{T} / \mathrm{T}(0) \mathrm{T} / \mathrm{C}(0) \mathrm{C} / \mathrm{C}(30)$ \\
\hline rs138770371 & 316 & $\mathrm{G} / \mathrm{T}$ & 106 & $\mathrm{D} / \mathrm{Y}$ & G/G (0) G/T (0) T/T (59) & G/G (0) G/T (0) T/T (30) \\
\hline rs115324487 & 515 & $\mathrm{C} / \mathrm{T}$ & 172 & AN & $\mathrm{C} / \mathrm{C}(0) \mathrm{C} / \mathrm{T}(0) \mathrm{T} / \mathrm{T}(59)$ & $\mathrm{C} / \mathrm{C}(0) \mathrm{C} / \mathrm{T}(0) \mathrm{T} / \mathrm{T}(30)$ \\
\hline rs150746704 & 616 & $\mathrm{G} / \mathrm{C}$ & 206 & $\mathrm{~V} / \mathrm{L}$ & $\mathrm{G} / \mathrm{G}(0) \mathrm{G} / \mathrm{C}(0) \mathrm{C} / \mathrm{C}(59)$ & $\mathrm{G} / \mathrm{G}(0) \mathrm{G} / \mathrm{C}(0) \mathrm{C} / \mathrm{C}(30)$ \\
\hline rs4686302 & 652 & $\mathrm{~A} / \mathrm{G}$ & 218 & $\mathrm{~T} / \mathrm{A}$ & $\mathrm{A} / \mathrm{A}$ (3) $\mathrm{A} / \mathrm{G}(12) \mathrm{G} / \mathrm{G}$ (34) & $\mathrm{A} / \mathrm{A}(1) \mathrm{A} / \mathrm{G}(14) \mathrm{G} / \mathrm{G}(15)$ \\
\hline rs143908202 & 661 & $\mathrm{~A} / \mathrm{G}$ & 221 & $S / G$ & $\mathrm{~A} / \mathrm{A}(0) \mathrm{A} / \mathrm{G}(0) \mathrm{G} / \mathrm{G}(59)$ & $\mathrm{A} / \mathrm{A}(0) \mathrm{A} / \mathrm{G}(0) \mathrm{G} / \mathrm{G}(30)$ \\
\hline rs145921539 & 684 & $\mathrm{~T} / \mathrm{G}$ & 228 & C/W & $\mathrm{T} / \mathrm{T}(0) \mathrm{T} / \mathrm{G}(0) \mathrm{G} / \mathrm{G}(59)$ & $\mathrm{T} / \mathrm{T}(0) \mathrm{T} / \mathrm{G}(0) \mathrm{G} / \mathrm{G}(30)$ \\
\hline rs184175311 & 700 & $\mathrm{G} / \mathrm{A}$ & 234 & $E / K$ & G/G (0) G/A (0) A/A (59) & $\mathrm{G} / \mathrm{G}(0) \mathrm{G} / \mathrm{A}(0) \mathrm{A} / \mathrm{A}(30)$ \\
\hline rs61740241 & 712 & $\mathrm{~A} / \mathrm{G}$ & 238 & $\mathrm{~T} / \mathrm{A}$ & $\mathrm{A} / \mathrm{A}(0) \mathrm{A} / \mathrm{G}(0) \mathrm{G} / \mathrm{G}(59)$ & $\mathrm{A} / \mathrm{A}(0) \mathrm{A} / \mathrm{G}(0) \mathrm{G} / \mathrm{G}(30)$ \\
\hline rs151141371 & 755 & $\mathrm{C} / \mathrm{G}$ & 252 & $\mathrm{~A} / \mathrm{G}$ & $\mathrm{C} / \mathrm{C}(0) \mathrm{C} / \mathrm{G}(0) \mathrm{G} / \mathrm{G}(59)$ & $\mathrm{C} / \mathrm{C}(0) \mathrm{C} / \mathrm{G}(0) \mathrm{G} / \mathrm{G}(30)$ \\
\hline rs139854982 & 760 & $\mathrm{~T} / \mathrm{C}$ & 254 & $C / R$ & $\mathrm{~T} / \mathrm{T}(0) \mathrm{T} / \mathrm{C}(0) \mathrm{C} / \mathrm{C}(59)$ & $\mathrm{T} / \mathrm{T}(0) \mathrm{T} / \mathrm{C}(0) \mathrm{C} / \mathrm{C}(30)$ \\
\hline rs144366756 & 764 & $\mathrm{G} / \mathrm{T}$ & 255 & $\mathrm{GN}$ & G/G (0) G/T (0) T/T (59) & $\mathrm{G} / \mathrm{G}(0) \mathrm{G} / \mathrm{T}(0) \mathrm{T} / \mathrm{T}(30)$ \\
\hline rs237901 & 818 & $\mathrm{~T} / \mathrm{C}$ & 273 & $\mathrm{M} / \mathrm{T}$ & $\mathrm{T} / \mathrm{T}(0) \mathrm{T} / \mathrm{C}(0) \mathrm{C} / \mathrm{C}(59)$ & $\mathrm{T} / \mathrm{T}(0) \mathrm{T} / \mathrm{C}(0) \mathrm{C} / \mathrm{C}(30)$ \\
\hline rs144814761 & 841 & $\mathrm{~A} / \mathrm{G}$ & 281 & $\mathrm{MN}$ & A/A (0) A/G (0) G/G (59) & $\mathrm{A} / \mathrm{A}(0) \mathrm{A} / \mathrm{G}(0) \mathrm{G} / \mathrm{G}(30)$ \\
\hline rs140488139 & 963 & $\mathrm{~A} / \mathrm{C}$ & 321 & $\mathrm{~K} / \mathrm{N}$ & $\mathrm{A} / \mathrm{A}(0) \mathrm{A} / \mathrm{C}(0) \mathrm{C} / \mathrm{C}(59)$ & $\mathrm{A} / \mathrm{A}(0) \mathrm{A} / \mathrm{C}(0) \mathrm{C} / \mathrm{C}(30)$ \\
\hline rs151257822 & 1001 & $\mathrm{~A} / \mathrm{G}$ & 334 & $\mathrm{D} / \mathrm{G}$ & $\mathrm{A} / \mathrm{A}(0) \mathrm{A} / \mathrm{G}(0) \mathrm{G} / \mathrm{G}(59)$ & $\mathrm{A} / \mathrm{A}(0) \mathrm{A} / \mathrm{G}(1) \mathrm{G} / \mathrm{G}(29)$ \\
\hline rs143927655 & 1015 & $A / G$ & 339 & KVE & A/A (0) A/G (0) G/G (59) & $\mathrm{A} / \mathrm{A}(0) \mathrm{A} / \mathrm{G}(0) \mathrm{G} / \mathrm{G}(30)$ \\
\hline rs148899442 & 1100 & $\mathrm{G} / \mathrm{A}$ & 367 & $\mathrm{~S} / \mathrm{N}$ & G/G (0) G/A (0) A/A (59) & $\mathrm{G} / \mathrm{G}(0) \mathrm{G} / \mathrm{A}(0) \mathrm{A} / \mathrm{A}(30)$ \\
\hline rs144289031 & 1121 & $\mathrm{~A} / \mathrm{G}$ & 374 & $N / S$ & A/A (0) A/G (0) G/G (59) & $\mathrm{A} / \mathrm{A}(0) \mathrm{A} / \mathrm{G}(0) \mathrm{G} / \mathrm{G}(30)$ \\
\hline rs35062132 & 1126 & $\mathrm{G} / \mathrm{C}$ & 376 & $\mathrm{G} / \mathrm{R}$ & G/G (0) G/C (2) C/C (57) & G/G (0) G/C (0) C/C (29) \\
\hline rs35062132 & 1126 & $\mathrm{~T} / \mathrm{C}$ & 376 & $C / R$ & $\mathrm{~T} / \mathrm{T}(0) \mathrm{T} / \mathrm{C}(0) \mathrm{C} / \mathrm{C}(57)$ & $\mathrm{T} / \mathrm{T}(0) \mathrm{T} / \mathrm{C}(1) \mathrm{C} / \mathrm{C}(29)$ \\
\hline
\end{tabular}

${ }^{\mathrm{a}}$ IDs are from dbSNP of the National Center for Biotechnology Information [40]. Bold IDs indicate the presence of allelic heterozygosity. ${ }^{\mathrm{b}} \mathrm{A}$ of the ATG of the initial methionine is denoted nucleotide +1 .

internalization and trafficking. HEK-293 cells transfected with an expression plasmid for hOXTR-376R, hOXTR376G, or hOXTR-376C were stimulated with $100 \mathrm{nM}$ OXT for 5, 10, 15, 30, 45, 60, 90, and $120 \mathrm{~min}$. At each time point, the cells were fixed and stained with antibody pecific for the amino $(N)$-terminus, located extracellularly, of the OXTR under impermeable conditions. The specificity of the staining was confirmed by the comparison with the staining of mock-transfected and non-transfected HEK-293 cells (Additional file 1: Figure S1).

Immunoreactivity for hOXTRs was visualized by confocal laser scanning microscopy (Figure 2A). Immunofluorescence was measured and expressed as a percentage of the intensity for receptors remaining at the cell surface. Cell-surface intensity for hOXTR-376R reached the lowest value of $43.9 \pm 2.3 \%(n=30)$ after $60 \mathrm{~min}$, and then gradually increased to $77.1 \pm 8.7 \%(n=29)$ of the prestimulatory level at $120 \mathrm{~min}$. OXT-induced internalization in the cells expressing hOXTR-376C were very similar to that for hOXTR-376R: the surface intensity decreased to $45.1 \pm 3.3 \%(n=30)$ at $60 \mathrm{~min}$, and then elevated to $79.4 \pm 18.1 \%(n=8)$ at $120 \mathrm{~min}$. In contrast, the surface intensity of hOXTR-376G showed a significantly faster decrease than that for hOXTR-376R at 5 min after OXT application $(62.5 \pm 4.7 \%(n=25)$ for hOXTR-376G, $78.7 \pm 6.7 \%(n=15)$ for hOXTR-376R; $P<0.05$; Student's $t$ test). In addition, hOXTR-376G showed significantly higher levels of surface intensities from $30 \mathrm{~min}$ to $120 \mathrm{~min}$ after OXT application (Figure 2B). The values at $30,45,60$, and $120 \mathrm{~min}$ were $59.6 \pm$ 2.7 ( $n=30, P<0.05$; Student's $t$ test), $61.4 \pm 3.0$ ( $n=30$, $P<0.05$; Student's $t$ test), $67.7 \pm 3.7(n=30, P<0.01$; Student's $t$ test), and $96.1 \pm 6.6 \%(n=23, P<0.05$; Student's $t$ test) for hOXTR-376G, compared with $52.0 \pm 2.5(n=30)$, 
Table 3 Comparison of the genotype and allele frequencies of rs35062132 at Kanazawa University Hospital for ASDs

\begin{tabular}{lllll}
\hline & $\begin{array}{l}\text { Cases } \\
(\boldsymbol{n}=\mathbf{1 3 2})\end{array}$ & $\begin{array}{l}\text { Control } \\
(\boldsymbol{n}=\mathbf{2 4 8})\end{array}$ & $\begin{array}{l}\text { Odds ratio } \\
(\mathbf{9 5 \%} \mathrm{Cl})\end{array}$ & $\boldsymbol{P}$ \\
\hline Genotype & & & & \\
\hline $\mathrm{C} / \mathrm{C}$ & $125(94.7 \%)$ & $243(98.0 \%)$ & Referent & \\
\hline $\mathrm{C} / \mathrm{G}$ & $6(4.5 \%)$ & $2(0.8 \%)$ & $5.83(1.16,29.3)$ & 0.024 \\
\hline $\mathrm{C} / \mathrm{T}$ & $1(0.8 \%)$ & $3(1.2 \%)$ & $0.65(0.07,6.30)$ & 1.00 \\
\hline $\mathrm{G} / \mathrm{G}$ & 0 & 0 & & \\
\hline $\mathrm{T} / \mathrm{T}$ & 0 & 0 & & \\
\hline $\mathrm{G} / \mathrm{T}$ & 0 & 0 & & \\
\hline Allele & & & & \\
\hline $\mathrm{C}$ & $257(97.3 \%)$ & $491(99.0 \%)$ & Referent & \\
\hline $\mathrm{G}$ & $6(2.3 \%)$ & $2(0.4 \%)$ & $5.73(1.15,28.6)$ & 0.024 \\
\hline $\mathrm{T}$ & $1(0.4 \%)$ & $3(0.6 \%)$ & $0.64(0.07,6.16)$ & 1.00 \\
\hline $\mathrm{Cl}$, confidence interval. $\boldsymbol{P}$ values obtained by Fisher's exact test are given.
\end{tabular}

$\mathrm{Cl}$, confidence interval. $P$ values obtained by Fisher's exact test are given.
$51.1 \pm 3.1(n=30), 43.9 \pm 2.3(n=30)$, and $77.1 \pm 8.7 \%$ $(n=29)$ for hOXTR-376R, respectively (Figure $2 \mathrm{~B})$. The majority of the hOXTR-immunoreactivity was colocalized with fluorescence for $\mathrm{SNAP}_{\mathrm{f}}$-tagged $\beta 2$-adrenergic receptor as a plasma membrane marker ( $>84 \%$; Additional file 2 : Figure S2). These data demonstrate that, upon agonist stimulation, hOXTR-376G is internalized into the cytoplasm and recycled to the plasma membrane more rapidly than hOXTR-376R and hOXTR-376C.

\section{Agonist-induced $\mathrm{Ca}^{2+}$ mobilization in HEK-293 cells and NG108-15 neuronal cells}

To examine whether the amino acid substitutions altered the coupling to intracellular signaling system, we measured OXT-induced $\mathrm{Ca}^{2+}$ mobilization. Both HEK-293 cells and NG108-15 neuroblastoma $\times$ glioma hybrid cells were transfected with an expression plasmid for EGFP-tagged hOXTR-376R, hOXTR-R376G, or hOXTR-376C. Before OXT stimulation, EGFP fluorescence was homogenously distributed in both HEK-293 cells and NG108-15 neuronal cells expressing hOXTR-376R-EGFP, hOXTR-376G-EGFP, and hOXTR-376C-EGFP, as previously reported [13]
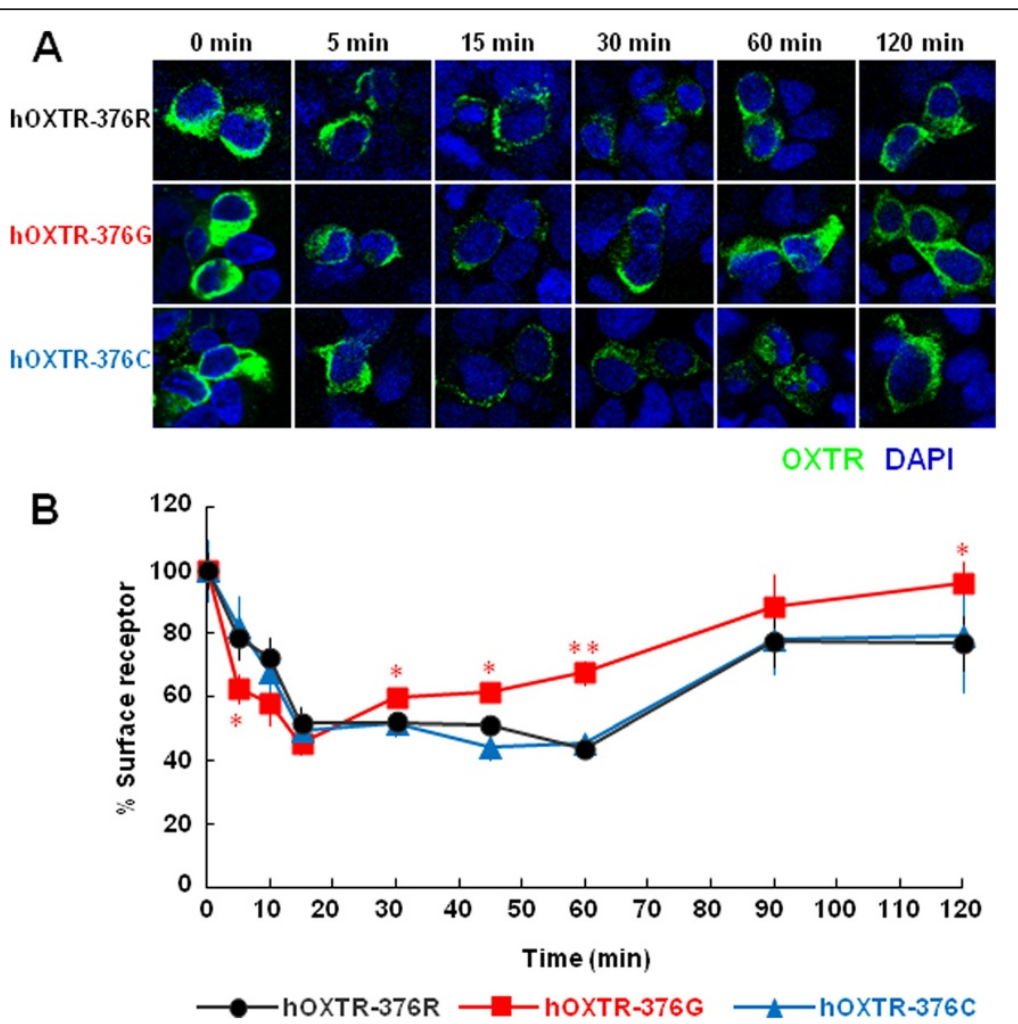

Figure 2 Agonist-induced internalization and recycling of common and variant hOXTRs. (A) Fluorescent images of HEK-293 cells transfected with expression plasmids for the common-type hOXTR-376R and variants hOXTR-376G and hOXTR-R376C. Cells were double-labeled using antibody against the N-terminus of hOXTR (Alexa Fluor 488, green) and a nuclear marker (DAPI, blue). Images were obtained by confocal laser scanning microscopy at the indicated time points after the addition of OXT (100 nM). (B) Fluorescence intensities for hOXTRs were quantified and expressed as the percentage of receptors remaining at the cell surface. Data are mean \pm standard error of the mean $(n=15$ to 30 cells from five cultures). Statistical significance was evaluated by the Student's $t$ test ( $P<0.05$, ${ }^{*} P<0.01$; compared with hOXTR-376R). 
(Figure 3A,B). After loading these cells with $\mathrm{Ca}^{2+}$-sensitive fluorescent dye fura-2/AM, the effect of the amino acid variations on OXT-induced increase in $\left[\mathrm{Ca}^{2+}\right]_{\mathrm{i}}$ was analyzed using a dual-wavelength (340 and $380 \mathrm{~nm}$ ) fluorescence spectrophotometer.

The addition of 100 nM OXT to HEK-293 cells expressing hOXTR-376R-EGFP induced a rapid initial increase of $\left[\mathrm{Ca}^{2+}\right]_{\mathrm{i}}$; the levels reached $223 \pm 19.6 \%(n=24)$ of the prestimulatory level and then returned to the basal level within $3 \mathrm{~min}$ (Figure 3C,E). In contrast, both hOXTR376G-EGFP- and hOXTR-376C-EGFP-expressing HEK293 cells exhibited significantly smaller initial peaks: the maximum $\left[\mathrm{Ca}^{2+}\right]_{\mathrm{i}}$ was $142 \pm 13.2 \%(n=24)$ and $159 \pm 3.8 \%(n=31)$ for hOXTR-376G-EGFP and hOXTR376C-EGFP, respectively (Figure 3C,E). Mock-transfected control cells did not show $\mathrm{Ca}^{2+}$ mobilization at all (Figure 3C,E).

The same tendency was observed in NG108-15 neuronal cells. $\left[\mathrm{Ca}^{2+}\right]_{\mathrm{i}}$ initially increased to relatively low levels compared with those in HEK-293 cells. The maximum $\left[\mathrm{Ca}^{2+}\right]_{\mathrm{i}}$ levels at the initial peak in hOXTR-376G-EGFPand hOXTR-376C-EGFP-expressing NG108-15 cells were $137 \pm 5.1 \%(n=28)$ and $128 \pm 2.0 \%(n=18)$, respectively, significantly lower than those in hOXTR-376R-EGFPexpressing cells, which reached $161 \pm 5.1 \%(n=24$; Figure 3D,F).

\section{Agonist dose-dependent $\mathrm{Ca}^{2+}$ mobilization}

We further examined the OXT dose-dependence during the increase in $\left[\mathrm{Ca}^{2+}\right]_{\mathrm{i}}$ in HEK-293 cells expressing the common and variant hOXTRs. OXT concentrations ranging from $10^{-11}$ to $10^{-6} \mathrm{M}$ were tested. When the OXT concentration was lower than $10^{-10} \mathrm{M}$, no differences in the initial $\left[\mathrm{Ca}^{2+}\right]_{\mathrm{i}}$ rise were observed in the cells expressing hOXTR-376R-EGFP, hOXTR-376G-EGFP, and hOXTR-376C-EGFP (Figure 4A,B). In the cells expressing hOXTR-376R-EGFP, the maximum initial increase in $\left[\mathrm{Ca}^{2+}\right]_{\mathrm{i}}$ was at $10^{-7} \mathrm{M}$ OXT (Figure $4 \mathrm{~A}, \mathrm{~B}$ ).

In HEK293 cells expressing hOXTR-376G-EGFP, the maximal $\left[\mathrm{Ca}^{2+}\right]_{\mathrm{i}}$ increase was obtained at $10^{-8} \mathrm{M}$ OXT $(158 \pm 5.2 \%(n=24)$; Figure $4 \mathrm{~A}, \mathrm{~B})$. OXT at $10^{-7}$ and $10^{-6}$ $\mathrm{M}$ resulted in significantly smaller $\left[\mathrm{Ca}^{2+}\right]_{\mathrm{i}}$ increases compared with those for hOXTR-376R-EGFP, with initial peak values being $142 \pm 13.2 \%(n=24)$ and $129 \pm$ $7.2 \%(n=16)$, respectively.

In HEK-293 cells expressing hOXTR-376C-EGFP, the maximal $\left[\mathrm{Ca}^{2+}\right]_{\mathrm{i}}$ increase was obtained at $10^{-7} \mathrm{M}$ $(159 \pm 3.8 \%(n=31)$; Figure $4 \mathrm{~A}, \mathrm{~B})$. At concentrations higher than $10^{-9} \mathrm{M}$, the OXT-induced increase in $\left[\mathrm{Ca}^{2+}\right]_{\mathrm{i}}$ was significantly reduced (Figure 4A,B). These data suggested that the rs35062132 variations (R376G/C) might alter the OXTR-mediated changes in the intracellular calcium concentrations.

\section{Agonist-induced $\mathrm{IP}_{3}$ accumulation in HEK-293 cells}

$\mathrm{IP}_{3}$ is known to mediate OXT-induced increase in $\left[\mathrm{Ca}^{2+}\right]_{\mathrm{i}}$ levels. Therefore, we investigated whether the amino acid substitutions could affect $\mathrm{IP}_{3}$ production. As shown in Figure 5, in HEK-293 cells expressing hOXTR-376R-EGFP, $100 \mathrm{nM}$ OXT elicited an increase in $\mathrm{IP}_{3}$ level within initial $10 \mathrm{~s}$; this increase was maintained for $30 \mathrm{~s}$ and the level returned to its basal value after $3 \mathrm{~min}$. Mock-transfected cells did not show any changes. The cells expressing hOXTR-376G-EGFP and hOXTR-376C-EGFP also stimulated $\mathrm{IP}_{3}$ production. During the whole period of $3 \mathrm{~min}$ after OXT application, $\mathrm{IP}_{3}$ production in cells expressing hOXTR-376G-EGFP was not statistically different compared with hOXTR-376R-EGFP $(P=0.1705, \mathrm{~F}(1,217)=$ 1.89; two-way ANOVA), whereas cells expressing hOXTR-376C-EGFP showed significantly smaller $\mathrm{IP}_{3}$ production $(P=0.003, \mathrm{~F}(1,210)=9.01$; two-way ANOVA). During the initial 5 to $30 \mathrm{~s}$ after OXT application, a slight but significant drop from the maximum $\mathrm{IP}_{3}$ levels was observed in these cells, compared with the values for hOXTR-376R-EGFP $(P=0.0210, \mathrm{~F}(1,107)=5.49$ for hOXTR-376G-EGFP; $P=0.0209, \mathrm{~F}(1,103)=5.5$ for hOXTR-376C-EGFP; two-way ANOVA).

\section{Discussion}

The main findings of this study are as follows. (i) Triallelic non-synonymous variation (rs35062132, c.1126C>G/T; $\mathrm{R} 376 \mathrm{G} / \mathrm{C}$ ) is observed in both ASD patients and healthy controls in a Japanese population; the frequencies of the $G$ allele are significantly higher in the ASD patients than in healthy controls. (ii) In HEK-293 cells expressing hOXTR$376 \mathrm{G}$, the agonist-induced internalization and recycling of the OXTR are faster than that in the cells expressing hOXTR-376C or hOXTR-376R. (iii) In both HEK-293 cells and NG108-15 neuronal cells, the agonist-induced increase in $\left[\mathrm{Ca}^{2+}\right]_{\mathrm{i}}$ mediated by hOXTR-376G-EGFP or hOXTR-376C-EGFP is smaller than the increase associated with hOXTR-376R-EGFP. These results provide new insights into the genetic architecture and therapeutic aspects of ASDs.

The present study is unique in associating nonsynonymous allelic variations of the OXTR gene with ASDs. These variations at rs35062132 have not been reported in other disorders. To date, several studies have found ASD-associated SNPs in the OXTR gene, which reside in introns (rs4564970 [41], rs237897 [25], rs53576 [23,24], rs2254298 [23-25], rs2268493 [42], rs7632287 [42], rs11720238 [41]), 3'-untranslated region (rs1042778) [42], and intergenic regions (rs7632287 and rs11720238) [41]. The functional consequences of these SNPs remain unclear. Importantly, all minor alleles of these SNPs have a frequency more than $5 \%$, and thus can be classified as common variations. In contrast, the frequencies of the $\mathrm{G}$ and $\mathrm{T}$ alleles of rs35062132 are $0.4 \%$ and $0.6 \%$, 


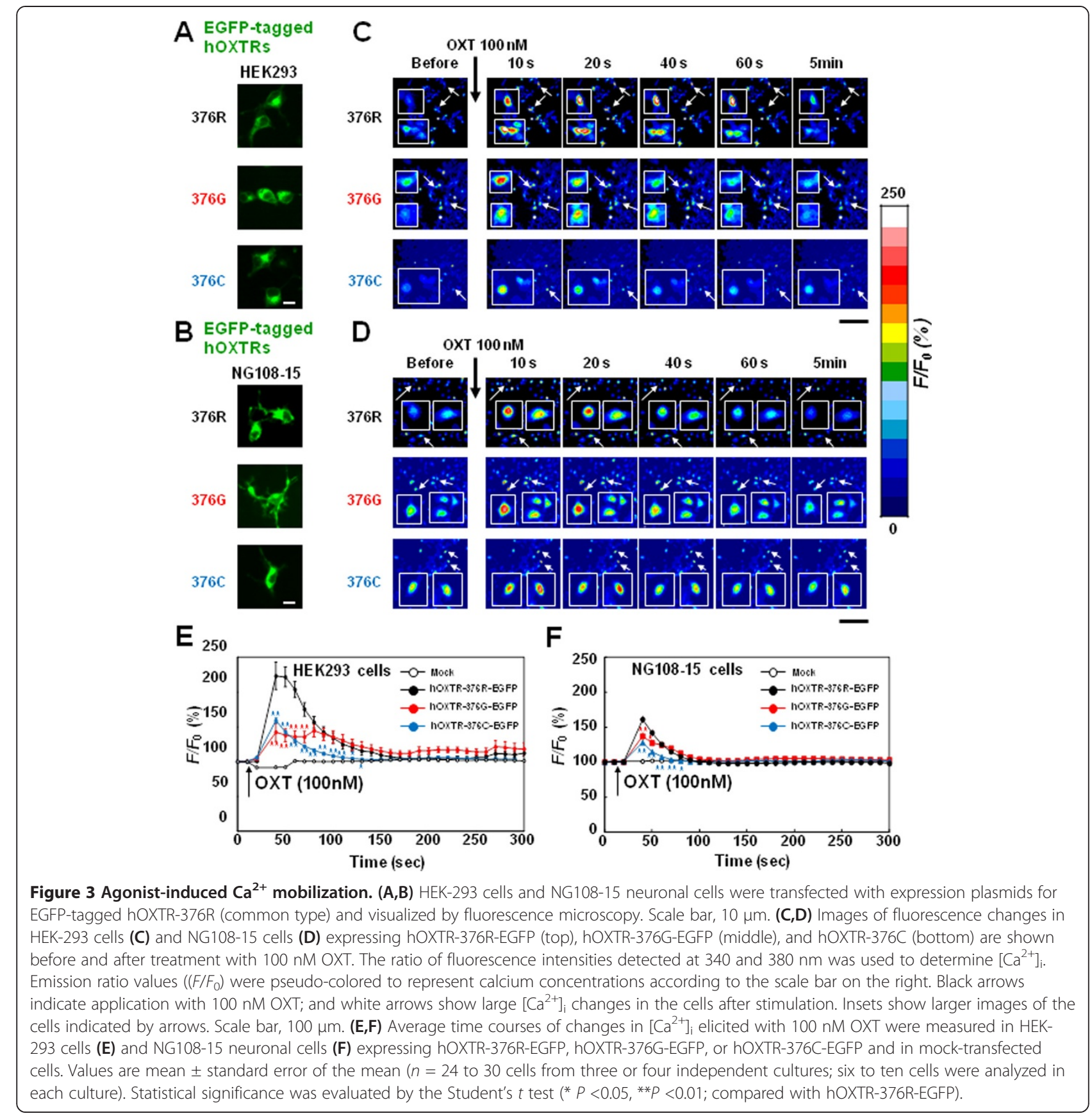

respectively, in controls; these minor alleles can be categorized as rare [43-45]. Therefore, most previous studies favor the common disease-common variant model, in which most of the risk is caused by common genetic variations ( $>5 \%$ allele frequency), each allele conferring a slight risk [43-47]. By contrast, our results support the common disease-rare variant model, in which the risk is mostly attributable to rare variations ( $<5 \%$ allele frequency), each variant conferring a moderate but readily detectable increase in the relative risk [43-47]. In agreement with this model, we observed that the minor alleles clearly affected OXT-induced cellular responses. Future studies will be conducted to test whether behavioral changes caused by these variations are moderate and reasonably deleterious. Also it will be interesting to examine whether the rs35062132 variations cosegregate with the risk alleles in the non-coding region [22-24,41,42].

The limitation of this study is that sample size is not sufficient to analyze the rare variant alleles at rs35062132. Future studies with larger sample size or family-based association testing are necessary to conclude that the G allele of the rs35062132 is a genetic risk factor for ASDs. 

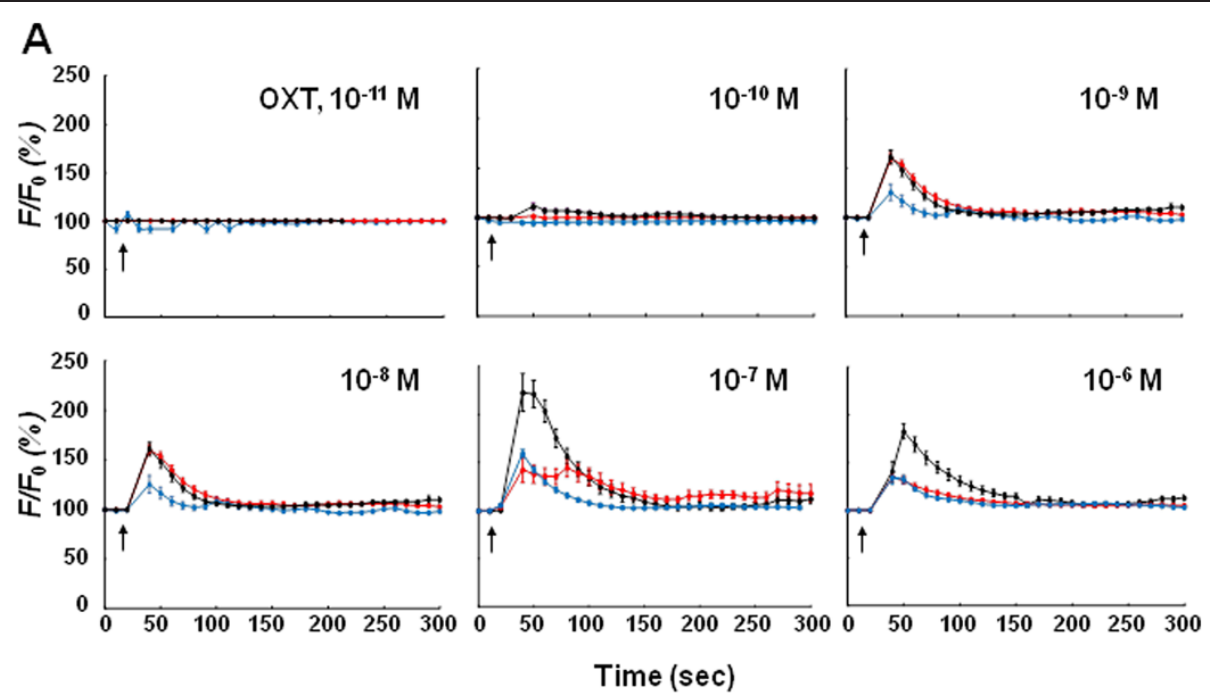

B
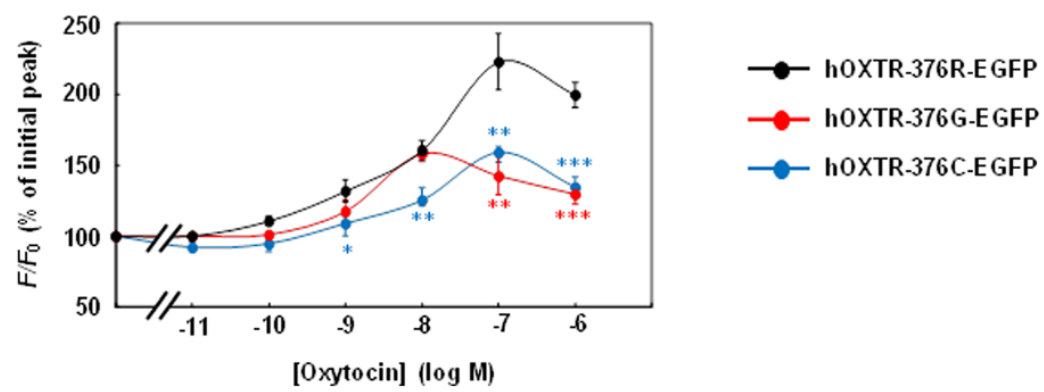

Figure 4 Agonist dose-dependent $\mathrm{Ca}^{2+}$ mobilization. (A) The changes in $\left[\mathrm{Ca}^{2+}\right]_{\mathrm{i}}$ induced by various concentrations of OXT were measured in HEK-293 cells expressing hOXTR-376R-EGFP, hOXTR-376G-EGFP, or hOXTR-376C-EGFP. (B) Relationship between OXT concentrations and [Ca $\left.{ }^{2+}\right]_{i}$ at the initial peak. Cells were infused with the indicated concentration of OXT. Each plot shows a percentage of $\left[\mathrm{Ca}^{2+}\right]_{i}$ at the initial peak after treatment with OXT. Data are mean \pm standard error of the mean ( $n=8$ to 30 cells from three or four independent cultures; two to eight cells were analyzed in each culture). Statistical significance was evaluated by the Student's $t$ test $\left(* P<0.05,{ }^{* *} P<0.01\right.$; compared with hOXTR-376R-EGFP).

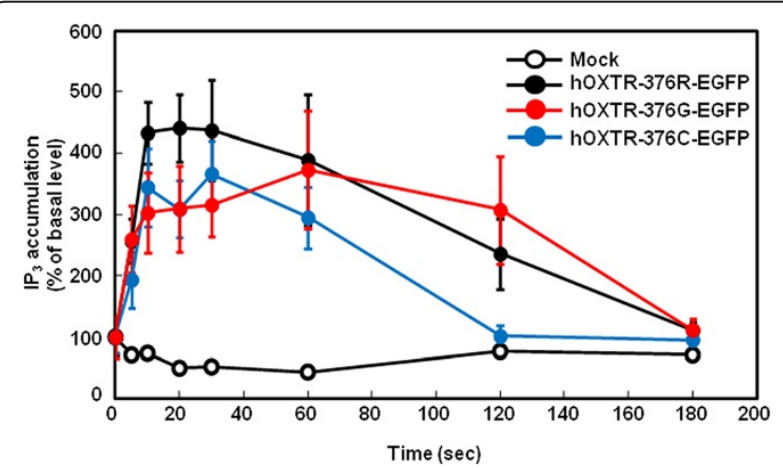

Figure 5 Agonist-induced $I_{P_{3}}$ accumulation. Average time courses of changes in $\mathrm{P}_{3}$ accumulation elicited with 100 nM OXT; $\mathrm{IP}_{3}$ levels were measured in HEK293 cells expressing hOXTR-376REGFP, hOXTR-376G-EGFP, and hOXTR-376C-EGFP. Data are expressed as mean \pm standard error of the mean ( $n=13$ to 15 cultures from five independent experiments). During the initial 5 to $30 \mathrm{~s}$ after OXT application, a significant drop from the maximum $\mathrm{IP}_{3}$ levels was observed in these cells $(P=0.0210, F(1,107)=5.49$ for hOXTR-376G -EGFP; $P=0.0209, F(1,103)=5.5$ for hOXTR-376C-EGFP; compared with the values for hOXTR-376R-EGFP; two-way ANOVA).
The result reported here should be replicated in independent populations with various ethnic backgrounds.

The amino acid variation $\mathrm{R} 376 \mathrm{G} / \mathrm{C}$ is located in the intracellular carboxy $(C)$-terminal tail of the receptor protein, which is critical for desensitization, internalization, and recycling of the OXTR, as in many other GPCRs [9-13]. $\mathrm{Arg}^{376}$ is associated with two structural components involved in these processes: (i) $\mathrm{Arg}^{376}$ is a part of a PKC consensus motif ( $\mathrm{Ser}^{374}-\mathrm{His}^{375}-\mathrm{Arg}^{376}$; Figure 1A), which is thought to interact with PKC after OXT stimulation [10]; and (ii) $\mathrm{Arg}^{376}$ is in conjunction with one of the two Ser triplets in the $C$-terminus (Figure $1 \mathrm{~A}$ ) that are primary sites of agonist-induced phosphorylation and $\beta$-arrestin-2 binding [11]. When either one of the two Ser triplets was mutated to alanine residues, the stability of the $\beta$-arrestin -2-OXTR complex was altered, and the ability of $\beta$ arrestin-2 to internalize with the receptor was eliminated [11]. In the vasopressin receptor V2, which is highly homologous to OXTR in structure, the equivalent Ser triplets function as a retention motif. GRK phosphorylation of these Ser residues promotes the 
formation of stable receptor- $\beta$-arrestin complexes, followed by cotrafficking and colocalization of the complexes to endocytotic vesicles and slow recycling to the cell surface [48]. Therefore, it is suggested that the R376G substitution in the OXTR might suppress the phosphorylation of Ser residues in the Ser triplets or reduce the stability of $\beta$-arrestin binding to the triplets, resulting in faster receptor recycling.

We demonstrated that, both in HEK-293 cells and in NG108-15 neuronal cells, agonist-induced $\left[\mathrm{Ca}^{2+}\right]_{\mathrm{i}}$ elevation mediated by variant receptors, hOXTR-376G-EGFP and hOXTR-376C-EGFP, is smaller than that by the common receptor hOXTR-376R-EGFP. Despite the marked reduction in the peak $\left[\mathrm{Ca}^{2+}\right]_{\mathrm{i}}$, the decrease in $\mathrm{IP}_{3}$ levels was slight. Provided that $\mathrm{Arg}^{376}$ is not located in the known site for $G_{q}$ binding (Figure $1 A$ ) [49], the $G_{q / 11} / P C_{\beta} / \mathrm{IP}_{3}$ independent, unidentified signaling pathway for $\left[\mathrm{Ca}^{2+}\right]_{i}$ elevation might be affected by the R376G/C substitution.

$\mathrm{Ca}^{2+}$ signaling pathways in neurons have been implicated in the pathogenesis of ASDs [50]. However, the involvement of OXTR-mediated, $\mathrm{PLC} / \mathrm{IP}_{3}$-dependent $\mathrm{Ca}^{2+}$ signaling in ASDs is still largely unknown. Recently, Ninan [51] has demonstrated that U73122, a PLC inhibitor, reduced OXT-induced suppression of glutamatergic synaptic transmission in pyramidal neurons of the medial prefrontal cortex, possibly by inhibiting PLC-dependent increase in postsynaptic calcium. Given that this process is critical for the OXT effects on social cognition, it is conceivable that the OXTR variations may serve as a risk factor for ASDs.

We have previously demonstrated that cADPR, which may act as an intracellular second messenger downstream of the OXTR, activates $\mathrm{Ca}^{2+}$ release from intracellular stores through the ryanodine receptor $\mathrm{Ca}^{2+}$ release channel. cADPR also initiates $\mathrm{Ca}^{2+}$ influx through melastatinrelated transient receptor potential 2 (TRPM2) channels [38]. Our previous SNP analysis has suggested that R140W substitution of CD38 protein, a regulator of ryanodine receptor-mediated $\mathrm{Ca}^{2+}$-induced $\mathrm{Ca}^{2+}$ release for OXT secretion [17], could be a potential risk factor for a subset of Japanese ASD patients [31]. Although this study shares a part of the ASD patients with our previous analysis [31], the 140W allele of CD38 has not been found in the patients carrying the OXTR-376G or OXTR-376C until now (unpublished data). It is therefore conceivable that the underlying signaling process affected by the R376G/C substitution is independent of the CD38-mediated OXT release from hypothalamic neurons [17].

Besides their relevance to the etiology of ASDs, the results presented here might contribute to the development of new pharmacological treatments. Genetic polymorphisms of many drug targets predict responsiveness to drugs [52,53]. It is likely that the alteration in the cellular functions mediated by the variant OXTRs could cause some individual differences in both behavioral and nonbehavioral responses to OXT. Although no side effects specific to intranasal OXT administration have been reported [54], new clinical information regarding functional OXTR variants will be helpful in the determination of individual administration protocols to maximize therapeutic benefit with least adverse effects.

\section{Conclusions}

Our analysis of the genetic variation rs35062132 in the human OXTR gene may be important for both etiological and therapeutic aspects of ASDs. However, the results reported here should be reproduced in an independent population. Further studies with a larger sample size using subjects of different ethnicities are required to confirm that the $\mathrm{G}$ allele of the rs35062132 is a genetic risk factor for ASDs. Identifying rare functional variants of the OXTR will shed new light on the genetic architecture of ASDs and allow personalized pharmacological intervention using OXT.

\section{Additional files}

\begin{abstract}
Additional file 1: Figure S1. Antibody validation. Fluorescent images of HEK-293 cells transfected with expression plasmids for the common-type hOXTR-376R (top, left) and variants hOXTR-376G (top, middle) and hOXTR$376 C$ (top, right). Images of HEK-293 cells transfected with an empty vector (Mock) and non-transected cells (-). Cells were stained with anti-hOXTR antibody and visualized with Alexa Fluor 488-conjugated secondary antibody (green). DAPI was used to stain cell nuclei (blue). Note that hOXTR-immunoreactivity is detected in cells transfected with expression plasmids for the common and variant hOXTRs but not in mock- and nontransfected cells. hOXTR-immunoreactive cells were detected in 11.8\% (177/ 1500 DAPI-positive cells in total of eight different fields), $15.5 \%$ (188/1210 in total of eight different fields), $16.6 \%$ (224/1353 in total of eight different fields), $0 \%$ (0/789 in total of four different fields), and 0\% (0/748 in total of four different fields) in hOXTR-376R-, hOXTR-376G-, hOXTR-376C-, mock-, and non-transfected cells, respectively. Scale bar, $20 \mu \mathrm{m}$.

Additional file 2: Figure S2. Co-staining of hOXTRs with $\beta 2$-adrenergic receptor as a cell-surface marker. (A) Fluorescent images of HEK-293 cells transfected with an expression plasmid for hOXTR-376R (left), hOXTR-376G (middle), or hOXTR-376C (right), together with that for the plasma membrane marker SNAPf-tagged $\beta 2$ adrenergic receptor. Cells were stained with antihOXTR antibody and visualized with Alexa Fluor 594-conjugated secondary antibody (hOXTR, red). SNAPf-tagged $\beta 2$ adrenergic receptor was labeled with SNAP-Surface Alexa Fluor 488 (SNAP $-A D R \beta 2$, green). DAPI was used to stain cell nuclei (DAPI, blue). Note that hOXTR-immunoreactivity is mostly overlapped with fluorescence for SNAP-tagged $\beta 2$ adrenergic receptor (Merge, yellow). Scale bar, 10 m. (B) OXTR-immunoreactivity overlapped with SNAP $_{\text {ftagged }} \beta 2$ adrenergic receptor. Data are mean \pm standard error of the mean. The overlapping at 0, 30, $60 \mathrm{~min}$ after OXT application (100 nM) was estimated to be $86.0 \pm 1.1 \%(n=20), 83.1 \pm 1.5 \%(n=18)$, and $85.5 \pm$ $1.0 \%$ at $60 \mathrm{~min}(n=20)$, respectively, for hOXTR-376R; $86.1 \pm 1.0 \%(n=23)$, $84.9 \pm 1.6 \%(n=13), 84.6 \pm 1.4 \%(n=20)$, respectively, for hOXTR-376G; and $85.2 \pm 1.2 \%(n=32), 84.9 \pm 1.8 \%(n=16)$, and $84.1 \pm 2.2 \%(n=19)$, respectively, for hOXTR-376C.
\end{abstract}

\section{Abbreviations}

ANOVA: Analysis of variance; ASD: Autism spectrum disorder; BSA: Bovine serum albumin; CADPR: cyclic ADP-ribose; Cl: Confidence interval; CREST: Core Research for Evolutional Science and Technology; DAPI: 4',6-diamidino-2phenylindole; DMEM: Dulbecco's modified Eagle's medium; EGFP: Enhanced green fluorescent protein; FBS: Fetal bovine serum; fura-2/AM: Fura-2- 
acetoxymethyl ester; hOXTR: Human oxytocin receptor; IP3: Inositol-1,4,5trisphosphate; MGB: Minor groove binder; OR: Odds ratio; OXT: Oxytocin; OXTR: Oxytocin receptor; PCR: Polymerase chain reaction; PKC: Protein kinase C; SNP: Single-nucleotide polymorphism.

\section{Competing interests}

The authors declare they have no competing interests.

\section{Authors' contributions}

$\mathrm{HH}$ and SY conceived and designed the research. WJM, TM, KH, KY, MY, and SY performed the genetic analysis of the ASD patients and healthy volunteers. WJM, MH, and SY carried out the experiments on cultured cells. WJM, HH, and SY analyzed data. WJM and SY drafted the initial manuscript: and WJM, TM, HH, and SY prepared successive versions of the document. All authors read and approved the final manuscript.

\section{Acknowledgements}

We thank Ms. Michiko Hoshii for technical assistance. This work was supported by grants-in-aid from the Japan Science and Technology Corporation (CREST), and 'Integrated research on neuropsychiatric disorders' carried out under the Strategic Research Program for Brain Sciences by the Ministry of Education, Culture, Sports, Science and Technology of Japan.

\section{Author details}

'Department of Biophysical Genetics, Kanazawa University Graduate School of Medicine, 13-1 Takara-machi, Kanazawa 920-8640, Japan. ${ }^{2}$ Research Center for Child Mental Development, Kanazawa University, Kanazawa 920-8640, Japan. ${ }^{3}$ Department of Clinical Laboratory, Kanazawa University Hospital, Kanazawa 920-8641, Japan. ${ }^{4}$ Department of Internal Medicine, Kanazawa University Graduate School of Medicine, Kanazawa 920-8640, Japan. ${ }^{5}$ Core Research for Evolutional Science and Technology (CREST), Japan Science and Technology Agency, Tokyo 102-0075, Japan. ${ }^{6}$ MEXT Strategic Research Program for Brain Sciences (SRPBS), Okazaki 444-0840, Japan.

Received: 28 September 2012 Accepted: 18 June 2013 Published: 1 July 2013

\section{References}

1. Carter CS, Grippo AJ, Pournajafi-Nazarloo H, Ruscio MG, Porges SW: Oxytocin, vasopressin and sociality. Prog Brain Res 2008, 170:331-336.

2. Donaldson ZR, Young $L$ : Oxytocin, vasopressin, and the neurogenetics of sociality. Science 2008, 322:900-904

3. Neumann ID: Brain oxytocin: a key regulator of emotional and social behaviours in both females and males. J Neuroendocrinol 2008 , 20:858-865.

4. McGregor IS, Callaghan PD, Hunt GE: From ultrasocial to antisocial: a role for oxytocin in the acute reinforcing effects and long-term adverse consequences of drug use? Br J Pharmacol 2008, 154:358-368.

5. Skuse DH, Gallagher L: Dopaminergic-neuropeptide interactions in the social brain. Trends Cogn Sci 2009, 13:27-35.

6. Meyer-Lindenberg A, Domes G, Kirsch P, Heinrichs M: Oxytocin and vasopressin in the human brain: social neuropeptides for translational medicine. Nat Rev Neurosci 2011, 12:524-538.

7. Ludwig M, Leng G: Dendritic peptide release and peptide-dependent behaviours. Nat Rev Neurosci 2006, 7:126-136.

8. Knobloch HS, Charlet A, Hoffmann LC, Eliava M, Khrulev S, Cetin AH, Osten P, Schwarz MK, Seeburg PH, Stoop R, Grinevich V: Evoked axonal oxytocin release in the central amygdala attenuates fear response. Neuron 2012, 73:553-566

9. Gimpl G, Reitz J, Brauer S, Trossen C: Oxytocin receptors: ligand binding, signalling and cholesterol dependence. Prog Brain Res 2008, 170:193-204

10. Berrada K, Plesnicher CL, Luo X, Thibonnier M: Dynamic interaction of human vasopressin/oxytocin receptor subtypes with $\mathrm{G}$ protein-coupled receptor kinases and protein kinase $\mathrm{C}$ after agonist stimulation. J Biol Chem 2000, 275:27229-27237.

11. Oakley RH, Laporte SA, Holt JA, Barak LS, Caron MG: Molecular determinants underlying the formation of stable intracellular $\mathrm{G}$ proteincoupled receptor- $\beta$-arrestin complexes after receptor endocytosis. J Biol Chem 2001, 276:19452-19460.
12. Hasbi A, Devost D, Laporte SA, Zingg HH: Real-time detection of interactions between the human oxytocin receptor and $\mathrm{G}$ proteincoupled receptor kinase-2. Mol Endocrinol 2004, 18:1277-1286.

13. Conti F, Sertic S, Reversi A, Chini B: Intracellular trafficking of the human oxytocin receptor: evidence of receptor recycling via a Rab4/Rab5 "short cycle". Am J Physiol Endocrinol Metab 2009, 29:E532-E542.

14. Ferguson JN, Young LJ, Hearn EF, Matzuk MM, Insel TR, Winslow JT: Social amnesia in mice lacking the oxytocin gene. Nat Genet 2000, 25:284-288.

15. Takayanagi Y, Yoshida M, Bielsky IF, Ross HE, Kawamata M, Onaka T, Yanagisawa T, Kimura T, Matzuk MM, Young $\sqcup$, Nishimori K: Pervasive social deficits, but normal parturition, in oxytocin receptor-deficient mice. Proc Natl Acad Sci USA 2005, 102:16096-160101.

16. Sala M, Braida D, Lentini D, Busnelli M, Bulgheroni E, Capurro V, Finardi A, Donzelli A, Pattini L, Rubino T, Parolaro D, Nishimori K, Parenti M, Chini B: Pharmacologic rescue of impaired cognitive flexibility, social deficits, increased aggression, and seizure susceptibility in oxytocin receptor null mice: a neurobehavioral model of autism. Biol Psychiatry 2010, 69:875-882.

17. Jin D, Liu HX, Hirai H, Torashima T, Nagai T, Lopatina O, Shnayder NA, Yamada K, Noda M, Seike T, Fujita K, Takasawa S, Yokoyama S, Koizumi K, Shiraishi Y, Tanaka S, Hashii M, Yoshihara T, Higashida K, Islam MS, Yamada N, Hayashi K, Noguchi N, Kato I, Okamoto H, Matsushima A, Salmina A, Munesue T, Shimizu N, Mochida S, et al: CD38 is critical for social behaviour by regulating oxytocin secretion. Nature 2007, 446:41-45.

18. Liu HX, Lopatina O, Higashida C, Tsuji T, Kato I, Takasawa S, Okamoto H, Yokoyama S, Higashida H: Locomotor activity, ultrasonic vocalization and oxytocin levels in infant CD38 knockout mice. Neurosci Lett 2008, 448:67-70.

19. Lopatina O, Liu HX, Amina S, Hashii M, Higashida H: Oxytocin-induced elevation of ADP-ribosyl cyclase activity, cyclic ADP-ribose or $\mathrm{Ca}^{2+}$ concentrations is involved in autoregulation of oxytocin secretion in the hypothalamus and posterior pituitary in male mice. Neuropharmacology 2010, 58:50-55.

20. Graustella AJ, MacLeod C: A critical review of the influence of oxytocin nasal spray on social cognition in humans: evidence and future directions. Horm Behav 2012, 61:410-418.

21. Gregory SG, Connelly JJ, Towers AJ, Johnson J, Biscocho D, Markunas CA, Lintas C, Abramson RK, Wright HH, Ellis P, Langford CF, Worley G, Delong GR, Murphy SK, Cuccaro ML, Persico A, Pericak-Vance MA: Genomic and epigenetic evidence for oxytocin receptor deficiency in autism. BMC Med 2009, 7:62.

22. Wu S, Jia M, Ruan Y, Liu J, Guo Y, Shuang M, Gong X, Zhang Y, Yang X, Zhang D: Positive association of the oxytocin receptor gene (OXTR) with autism in the Chinese Han population. Biol Psychiatry 2005, 58:74-77.

23. Jacob S, Brune CW, Carter CS, Leventhal BL, Lord C, Cook EHJ: Association of the oxytocin receptor gene (OXTR) in Caucasian children and adolescents with autism. Neurosci Lett 2007, 417:6-9.

24. Lerer E, Levi S, Salomon S, Darvasi A, Yirmiya N, Ebstein RP: Association between the oxytocin receptor (OXTR) gene and autism: relationship to Vineland Adaptive Behavior Scales and cognition. Mol Psychiatry 2008, 13:980-988.

25. Yrigollen CM, Han SS, Kochetkova A, Babitz T, Chang JT, Volkmar FR, Leckman JF, Grigorenko EL: Genes controlling affiliative behavior as candidate genes for autism. Biol Psychiatry 2008, 63:911-916.

26. Ebstein RP, Israel S, Lerer E, Uzefovsky F, Shalev I, Gritsenko I, Riebold M, Salomon S, Yirmiya N: Arginine vasopressin and oxytocin modulate human social behavior. Ann NY Acad Sci 2009, 1167:87-102.

27. Liu X, Kawamura Y, Shimada T, Otowa T, Koishi S, Sugiyama T, Nishida H, Hashimoto O, Nakagami R, Tochigi M, Umekage T, Kano Y, Miyagawa T, Kato N, Tokunaga K, Sasaki T: Association of the oxytocin receptor (OXTR) gene polymorphisms with autism spectrum disorder (ASD) in the Japanese population. J Hum Genet 2010, 55:137-141.

28. Wermter AK, Kamp-Becker I, Hesse P, Schulte-Körne G, Strauch K Remschmidt $\mathrm{H}$ : Evidence for the involvement of genetic variation in the oxytocin receptor gene (OXTR) in the etiology of autistic disorders on high-functioning level. Am J Med Genet B Neuropsychiatr Genet 2010, 153B:629-639.

29. Meyer-Lindenberg A, Tost $\mathrm{H}$ : Neural mechanisms of social risk for psychiatric disorders. Nat Neurosci 2012, 15:663-668.

30. den Dunnen JT, Antonarakis SE: Mutation nomenclature extensions and suggestions to describe complex mutations: a discussion. Hum Mut 2000, $15: 7-12$ 
31. Munesue T, Yokoyama S, Nakamura K, Anitha A, Yamada K, Hayashi K, Asaka T, Liu HX, Jin D, Koizumi K, Islam MS, Huang JJ, Ma WJ, Kim UH, Kim SJ, Park K, Kim D, Kikuchi M, Ono Y, Nakatani H, Suda S, Miyachi T, Hirai H, Salmina A, Pichugina YA, Soumarokov AA, Takei N, Mori N, Tsujii M, Sugiyama T, et al: Two genetic variants of CD38 in subjects with autism spectrum disorder and controls. Neurosci Res 2010, 67:181-191.

32. Gillberg C, Gillberg C, Rastam M, Wentz E: The Asperger Syndrome (and high-functioning autism) Diagnostic Interview (ASDI): a preliminary study of a new structured clinical interview. Autism 2001, 5:57-66.

33. Lord C, Rutter M, Le Couteur A: Autism Diagnostic Interview-Revised: a revised version of a diagnostic interview for caregivers of individuals with possible pervasive developmental disorders. J Autism Dev Disord 1994, 24:659-685.

34. Autism Society Japan: Pervasive Developmental Disorders Autism Society Japan Rating Scale (PARS). Tokyo; 2006

35. Wing L, Leekam SR, Libby SJ, Gould J, Larcombe M: The Diagnostic Interview for Social and Communication Disorders: background, interrater reliability and clinical use. J Child Psychol Psychiat 2002, 43:307-325.

36. Kurita $H$, Miyake $Y$ : The reliability and validity of the Tokyo Autistic Behavior Scale. Psychiat Clin Neurosci 1990, 44:25-32.

37. Shenoy AR, Visweswariah SS: Site-directed mutagenesis using a single mutagenic oligonucleotide and Dpnl digestion of template DNA. Anal Biochem 2003, 319:335-336.

38. Amina S, Hashii M, Ma WJ, Yokoyama S, Lopatina O, Liu HX, Islam MS, Higashida $\mathrm{H}$ : Intracellular calcium elevation induced by extracellular application of cyclic-ADP-ribose or oxytocin is temperature-sensitive in rodent NG108-15 neuronal cells with or without exogenous expression of human oxytocin receptors. J Neuroendocrinol 2010, 22:460-466.

39. Hashii M, Minabe $Y$, Higashida H: CADP-ribose potentiates cytosolic $\mathrm{Ca}^{2+}$ elevation and $\mathrm{Ca}^{2+}$ entry via L-type voltage-activated $\mathrm{Ca}^{2+}$ channels in NG108-15 neuronal cells. Biochem J 2000, 345:207-215.

40. dbSNP Short Genetic Variations. [http://www.ncbi.n/m.nih.gov/SNP/]

41. Tansey KE, Brookes KJ, Hill MJ, Cochrane LE, Gill M, Skuse D, Correia C, Vicente A, Kent L, Gallagher L, Anney RJL: Oxytocin receptor (OXTR) does not play a major role in the aetiology of autism: genetic and molecular studies. Neurosci Lett 2010, 474:163-167.

42. Campbell DB, Datta D, Jones ST, Batey Lee E, Sutcliffe JS, Hammock EA, Levitt P: Association of oxytocin receptor (OXTR) gene variants with multiple phenotype domains of autism spectrum disorder. J Neurodev Disord 2011, 3:101-112.

43. Cirulli ET, Goldstein DB: Uncovering the roles of rare variants in common disease through whole-genome sequencing. Nat Rev Genet 2010, 11:415-425.

44. Geschwind DH: Genetics of autism spectrum disorders. Trends Cogn Sci 2011, 15:409-416.

45. State MW, Levitt $P$ : The conundrums of understanding genetic risks for autism spectrum disorders. Nat Neurosci 2011, 14:1499-1506.

46. Bodmer W, Bonilla C: Common and rare variants in multifactorial susceptibility to common diseases. Nat Genet 2008, 40:695-701.

47. Schork NJ, Murray SS, Frazer KA, Topol EJ: Common vs. rare allele hypotheses for complex diseases. Curr Opin Genet Dev 2009, 19:212-219.

48. Innamorati G, Sadeghi H, Eberle AN, Birnbaumer M: Phosphorylation of the V2 vasopressin receptor. J Biol Chem 1997, 272:2486-2492

49. Hoare S, Copland JA, Strakova Z, Ives K, Jeng YJ, Hellmich MR, Soloff MS: The proximal portion of the $\mathrm{COOH}$ terminus of the oxytocin receptor is required for coupling to $G_{q}$, but not $G_{i}$ : independent mechanisms for elevating intracellular calcium concentrations from intracellular stores. J Biol Chem 1999, 274:28682-28689.

50. Krey JF, Dolmetsch RE: Molecular mechanisms of autism: a possible role for $\mathrm{Ca}^{2+}$ signaling. Curr Opin Neurobiol 2007, 17:112-119.

51. Ninan I: Oxytocin suppresses basal glutamatergic transmission but facilitates activity-dependent synaptic potentiation in the medial prefrontal cortex. J Neurochem 2011, 119:324-331.

52. Ma Q, Lu AYH: Pharmacogenetics, pharmacogenomics, and individualized medicine. Pharmacol Rev 2011, 68:437-459.
53. Relling MV, Giacomini KM: Pharmacogenetics. In Goodman \& Gilman's The Pharmacological Basis of Therapeutics. 12th edition. Edited by Brunton LL. New York: McGraw-Hill; 2011:145-168.

54. MacDonald E, Dadds MR, Brennan JL, Williams K, Levy F, Cauchi AJ: A review of safety, side-effects and subjective reactions to intranasal oxytocin in human research. Psychoneuroendocrinology 2011, 36:1114-1126.

doi:10.1186/2040-2392-4-22

Cite this article as: Ma et al:: Non-synonymous single-nucleotide variations of the human oxytocin receptor gene and autism spectrum disorders: a case-control study in a Japanese population and functional analysis. Molecular Autism 2013 4:22.

\section{Submit your next manuscript to BioMed Central and take full advantage of:}

- Convenient online submission

- Thorough peer review

- No space constraints or color figure charges

- Immediate publication on acceptance

- Inclusion in PubMed, CAS, Scopus and Google Scholar

- Research which is freely available for redistribution
C Biomed Central 